\title{
RELAÇÕES DE GÊNERO E VULNERABILIDADE ÀS DOENÇAS SEXUALMENTE TRANSMISSIVEIS: PERCEPÇÕES SOBRE A SEXUALIDADE DOS ADOLESCENTES
}

\author{
Gender Relation and Vulnerability to Sexually \\ Transmissive Diseases: Perceptions of the Adolescents' Sexuality \\ Relaciones de Género y Vulnerabilidad a las Enfermedades \\ de Transmisión Sexual: Percepciones Sobre la Sexualidad de los Adolescentes
}

Cibele Almeida Torres

Eveline Pinheiro Beserra

Maria Grasiela Teixeira Barroso

\section{Resumo}

As questões de gênero são primordiais para o entendimento das relações de poder na sociedade, inclusive na sexualidade. Assim, o objetivo deste estudo é analisar a influência das relações de gênero no contexto dos adolescentes e as diferentes percepções dos gêneros quanto à vulnerabilidade às doenças sexualmente transmissíveis. Trata de uma abordagem qualitativa realizada a partir da técnica de grupo focal com adolescentes de Fortaleza, Ceará, Brasil. Percebeu-se pelo diálogo com os adolescentes, que a rede social não se sente responsabilizada pela vulnerabilidade em que os jovens se encontram. Os adolescentes do grupo focal masculino sentiram necessidade de apresentarem-se livres para expressarem seus desejos sexuais, detentores do comando na relação conjugal, e as adolescentes reproduziram a condição atual de submissão feminina aos desejos masculinos. Ambos os grupos encontraram-se vulneráveis às doenças sexualmente transmissíveis. Todo formato de sociedade contribui para a permanência de paradigmas que englobam a sexualidade.

Palavras-chave: Saúde do Adolescente. Sexualidade. Vulnerabilidade. Doenças Sexualmente Transmissíveis. Identidade de Gênero.

\section{Abstract}

Gender subjects are extremely important for the acknowledgements of the relationships of power amongst the society, including sexuality. The aim of this study is to analyze the influence of gender relations in the adolescents' context and different gender perceptions of the vulnerability to sexually transmissive diseases. This is a study with qualitative approach which used a focal group technique with adolescents of Fortaleza, Ceará, Brazil. Through the adolescents' dialogue it was found that the social network does not feel responsible for their vulnerability. The adolescents of the male focal group felt the need to freely express their sexual desires, withholders of authority in a conjugal relationship. The female focal group repeated the present condition of female submission towards the males' desires. Both groups are vulnerable to sexually transmissive diseases. The whole format of society contributes to the present paradigms, which embodies sexuality.

Keywords: Adolescent Health. Sexuality. Vulnerability. Sexually Transmissive Diseases. Gender Identity.

\section{Resumen}

Las cuestiones de género son primordiales para comprender las relaciones de poder en la sociedad, incluso en la sexualidad. Así, el objetivo de este estudio es analizar la influencia de las relaciones de género en el contexto de los adolescentes y las diferentes percepciones de los géneros cuanto a la vulnerabilidad a las enfermedades de transmisión sexual. Tratase de un abordaje cualitativo realizado a través de la técnica de grupo focal con adolescentes de Fortaleza, Ceará, Brasil. Fue percibido a través del diálogo con los adolescentes que la red social no se siente responsable por la vulnerabilidad en que los jóvenes se encuentran. Los adolescentes del grupo focal masculino sintieron necesidad de se presentaren libres para expresaren sus deseos sexuales, detenedores del comando en la relación conyugal y las adolescentes reproducieron la condición actual de sumisión femenina a los deseos masculinos. De esa manera, los dos sexos se encuentran vulnerables a las enfermedades de transmisión sexual. Todo formato de sociedad contribuye para la permanencia de paradigmas que envuelven la sexualidad.

Palabras clave: Salud del Adolescente. Sexualidad. Vulnerabilidad. Enfermedades de transmisión sexual. Identidad de género. 


\section{INTRODUÇÃO}

Durante séculos, as mulheres enfrentam batalhas para aniquilar o quadro cultural de subordinação e submissão no qual estão historicamente inseridas. As lutas e conquistas se dirigiam para garantir os direitos políticos, como o de votar e ser votadas, os direitos sociais e econômicos, como trabalho remunerado, estudo, propriedade, herança, até o direito ao corpo, ao prazer, à sexualidade, e contra o poder de subordinação das mulheres pelos homens'.

Dentre algumas questões que envolvem a mulher, há a reprodução e a sexualidade que vieram a ser separadas com maior segurança a partir de 1967, no Brasil, com o advento dos métodos contraceptivos modernos, entre estes as pílulas anticoncepcionais. 0 seu surgimento, no entanto, não aconteceu de forma tão emancipatória para a mulher, já que, nos países subdesenvolvidos, essa política, de caráter internacional, nasce muito mais voltada para o controle da natalidade?

Neste histórico de lutas, o movimento feminista veio pautar o debate, levando à frente as reivindicações femininas. Neste contexto, encontramos as filósofas, historiadoras, intelectuais e toda a massa que forma o movimento pelas causas femininas. Entendendo, porém, que ser mulher não é suficiente para tornar todas iguais e com os mesmos ideais; a diferenciação por sexo não é o bastante para centrar as pessoas nas mesmas lutas. É deste pensamento do movimento feminista que nasce nos anos 1980 a nova categoria gênero no lugar da antiga categoria mulher ou sexo, por ter a concepção de que as diferenciações comportamentais não eram determinadas pelo sexo biológico, mas influenciadas pelo gênero, refletidas na cultura ${ }^{1}$. Ambos os conceitos têm significados distintos. Sexo consiste no conjunto das características biológicas e naturais, essencialmente imutáveis. Já gênero é influenciado pelo contexto sociocultural estabelecido às pessoas no passar dos tempos e que são possivelmente mutáveis no decorrer da história. Atualmente as questões de gênero são primordiais para entender as relações distintas entre as pessoas e como estas influenciam nas relações de poder estabelecidas entre homens e mulheres na sociedade. Assim, essas relações desiguais são vistas nos diferentes âmbitos dos indivíduos e coletividade, inclusive na sexualidade e na vulnerabilidade a que os gêneros estão expostos.

Sabe-se que o método das pílulas anticoncepcionais trouxe para a mulher uma série de mudanças no campo das relações de gênero com seu acesso ao mercado de trabalho, ocupação de cargos de destaque, participação no meio sindical e partidário, enfim, a possibilidade de discernir, independentemente da vontade do companheiro, o momento propício para engravidar ou não, sendo também responsável pela fecundidade do casal. Por outro lado, se comparado com o método do preservativo masculino, percebe-se grande influência do homem ao longo do processo histórico no que se relaciona com seu uso, ficando a mulher, muitas vezes, à mercê do desejo do companheiro. Isso acontece, na maioria das vezes, pelo fato de as mulheres ainda se encontrarem em desvantagem no momento de negociação do uso do preservativo na relação sexual, principalmente as mais idosas e as que vivem em união estável ${ }^{3}$.

Graças ao atual formato das relações de gênero desiguais, as mulheres encontram-se em uma situação de grande vulnerabilidade em relação às doenças sexualmente transmissíveis (DSTs) em decorrência de seu comportamento sexual desprotegido, creditando confiança nos parceiros ${ }^{4}$.

Focando especificamente o público adolescente, sabe-se que eles formam um seleto grupo etário que passa por intensas mudanças nos quesitos biológicos, psíquicos e sociais. É uma etapa cheia de conflitos pessoais e interpessoais em que os adolescentes incorporam influências culturais de familiares, da mídia, dos amigos, enfim, da sociedade. Essas influências culturais repercutem diretamente nos seus comportamentos e atitudes ante as relações de gênero. É na adolescência que se percebe grande vulnerabilidade física, psicológica e social ${ }^{5}$. Esta vulnerabilidade pode ser entendida como a interação dos fatores individuais do ser com fatores sociais nos quais está envolvido, podendo tornar-se um indivíduo mais vulnerável ou menos, dependendo de sua capacidade de reinterpretar criticamente mensagens sociais de perigo $0^{6}$.

A partir desta problemática, objetiva-se com este estudo analisar a influência cultural nas relações de gênero dos adolescentes e as diferentes percepções dos gêneros feminino e masculino quanto à vulnerabilidade às DSTs.

\section{METODOLOGIA}

Este estudo constitui uma abordagem qualitativa realizada a partir da técnica de grupo focal, que possibilita analisar, de forma eficiente e em curto tempo, problemas na perspectiva da população, examinando suas percepções, conceitos, opiniões, expectativas, representações culturais, universo cultural e vocabular ${ }^{7}$. 0 número de participantes varia de seis a dez, sendo eles selecionados a partir das características em comum (sexo, idade ou ocupação), seguindo o objetivo central do estudo, formando uma amostra intencional ${ }^{(8)}$.

Realizou-se esta pesquisa com os adolescentes na faixa etária de 14 a 17 anos, estudantes da primeira série do Ensino Médio de um colégio estadual de um bairro periférico de Fortaleza, Ceará, Brasil. Os estudantes foram divididos por gênero em dois grupos focais - feminino e masculino totalizando oito participantes no primeiro grupo e nove no segundo. Ocorreram cinco encontros em uma mesma semana, cada qual com duração média de 90 minutos.

No primeiro encontro, promoveu-se uma discussão em torno das palavras norteadoras: saúde, risco, vulnerabilidade, prevenção e DST. No segundo, discutiu-se o que é a sexualidade no ponto de vista deles e como o assunto é visto na família, escola, mídia e sociedade. No terceiro, foram abordadas mais intensamente as relações de gênero. No quarto, reportou-se, prioritariamente, às DSTs. No quinto, realizaram-se técnicas grupais, jogos, encenações acerca do contexto sociocultural dos adolescentes em torno das DSTs. Em cada encontro, os grupos foram acompanhados por um moderador e um observador da equipe de pesquisa. 
Sabendo que em uma pesquisa qualitativa a etapa da análise de dados é um dos momentos mais importantes, é necessária uma apurada sistematização dos indicadores para se identificarem e classificarem as categorias mais significativas ${ }^{9}$. Segundo Bardin ${ }^{10}$, a análise de conteúdo é:

(...) um conjunto de técnicas de análise das comunicações visando obter, por procedimentos, sistemáticos e objectivos de descrição do conteúdo das mensagens, indicadores (quantitativos ou não) que permitam a inferência de conhecimentos relativos às condições de produção/recepção (variáveis inferidas) destas mensagens.

A análise de conteúdo, de Bardin, permite explicitar e sistematizar o conteúdo das mensagens e a expressão do conteúdo. 0 objetivo desta abordagem é efetuar deduções lógicas e justificadas, referentes à origem das mensagens do estudo, respeitando as questões políticas, psicológicas e sociológicas das expressões dos adolescentes. Assim, seguindo o roteiro utilizado nos encontros e a análise de conteúdo de Bardin, foram identificadas as principais variáveis temáticas, de acordo com a freqüência das falas, criando as categorias classificatórias. Os conteúdos mais significativos foram abordados, procurando excluir o viés de julgamento dos pesquisadores.

Aspectos legais e éticos que envolvem pesquisas com seres humanos foram respeitados, conforme a Resolução 196/96, do Conselho Nacional de Saúde - MS - Brasil ${ }^{11}$. A participação dos estudantes foi iniciada após sua assinatura do Termo de Consentimento Livre e Esclarecido e de seu responsável, garantindo sigilo e anonimato das pessoas participantes do estudo. Foi explicado ao estudante que a participação era livre, que a recusa em participar da pesquisa não Ihe causaria nenhuma restrição e que era obrigatória a prévia permissão dos pais. 0 projeto de pesquisa foi aprovado previamente pelo Comitê de Ética em Pesquisa da Universidade Federal do Ceará.

\section{RESULTADOS}

A partir da análise dos dados, classificamos os conteúdos mais relevantes em três categorias: "A conjuntura do mundo adolescente e sua vulnerabilidade", "Sexualidade e preconceitos enraizados" e "Relações de gênero como questão emergencial para reflexão".

\section{A conjuntura do mundo adolescente e sua vulnerabilidade}

0 universo do adolescente deve ser analisado de forma multifacetada, no qual os grupos sociais da família, escola, amigos, serviço de saúde e mídia são fundamentais na sua formação. Essa é uma questão relevante, quando se faz referência à sexualidade, já que a percepção juvenil é formulada justamente a partir de suas diversificadas experiências cotidianas. Assim, quando se repensa a condição de vulnerabilidade, a que 0 adolescente está frequentemente exposto, esses ambientes têm enorme responsabilidade. Durante os diálogos com os adolescentes participantes dos grupos focais, puderam-se ouvir depoimentos freqüentes acerca destes ambientes.
A família é apresentada pelas falas no grupo focal feminino: Meus pais nunca tiveram coragem de falar sobre sexo comigo. Acho que eles pensam que podem me estimular a querer fazer. Muitos pais têm vergonha. É muito difícil ter familia que converse. Os pais deviam pensar que a gente cresceu e que é melhor prevenir do que esconder os assuntos de nós. Essas falas do grupo focal feminino revelaram que a sexualidade ainda é tratada como tabu em suas famílias e, na maioria das vezes, o adolescente não consegue conversar com os pais sobre comportamentos sexuais, pois a sexualidade também é uma experiência confusa para eles e que não oferece um modelo de controle para os jovens ${ }^{12}$ A família deixa de pautar este assunto com a garota, por muitas vezes não percebê-la como mulher, que pode iniciar a vida sexual. Isto é percebido quando se comparam com falas do grupo focal masculino: Minha mãe conversa comigo de tudo e meu pai me dá camisinha e revista de mulher pelada. O pai sempre quer que o filho seja garanhão. As falas apontam para uma diferenciada forma de tratamento dos filhos: A familia influencia no comportamento: menino é solto e as meninas precisam de cuidado e proibições. A família reproduz a condição de que os garotos devam ser sexualmente capazes e potentes e que a garota deva ser passiva, dependente e sensível ${ }^{13}$. $\mathrm{E}$, assim, os adolescentes refletem igualmente a condição da sociedade em tratar os gêneros de forma diferenciada.

A escola aparece nos relatos como uma instituição que ainda nega o assunto sexualidade em seus programas de ensino: Aqui no colégio, nem me lembro quando falaram de sexualidade. $E$ muito difícil. Uma vez na vida o professor de Biologia conversa sobre esses assuntos com a gente. A escola devia conversar mais com a gente sobre esses assuntos. Os adolescentes têm muita curiosidade acerca da sexualidade e sentem falta de a escola cumprir este papel, já que ela detém a importante função de favorecer o pensamento crítico, o convívio com a diversidade e a participação juvenil e comunitária na formulação, gestão e controle social das políticas públicas ${ }^{14}$.

Com os amigos, a situação é diferente. Sem distinção de gênero, todos afirmam: Os amigos são quem mais ensinam a gente. A questão complica-se, porém, quando há uma grande influência não saudável: Cara, faz sem camisinha mesmo, é muito mais gostoso. Com as meninas é diferente dos meninos, com a gente as amigas aconselham, mas frescam com eles. Há forte relação dos adolescentes em quererem se afirmar dentro do grupo de amigos, por conta da insegurança típica da idade e da necessidade de aceitação, principalmente no grupo focal masculino. Essa questão apresenta-se como um dos contextos sociais que mais influencia a sexualidade deles, sabendo que esta faz parte de uma construção social perante as relações de socialização dos jovens, predominando o papel dos amigos, do grupo ${ }^{9}$

A unidade básica de saúde e os meios de comunicação, principalmente televisão e internet, são outros contextos que envolvem a formação dos adolescentes. A unidade básica é citada na seguinte situação: Duvido que algum de nós vá pegar camisinha no posto. Lá ta cheio de pessoa do bairro. O povo fofoca muito. Todos têm vergonha de adquirir preservativo masculino neste ambiente em razão do julgamento da comunidade. A diferença quanto ao gênero está na forma de 
adquirir o preservativo. Para as meninas a situação é: Não tenho coragem nem de comprar preservativo. É muito vergonhoso. As meninas sempre esperam que o parceiro tenha o preservativo na hora de usar, pois não consideram responsabilidade sua e isto aumenta a vulnerabilidade feminina, pois Ihes faltam a possibilidade de negociação e o domínio de suas relações sexuais em termos de fidelidade mútua e utilização da camisinha pelo homem ${ }^{15}$. Já os garotos afirmam que, sendo um local longe da comunidade onde residem, podem perfeitamente adquirir o preservativo, refletindo um empecilho enorme para o controle das DSTs. No geral, do ponto de vista dos adolescentes brasileiros, os serviços de saúde não representam um lugar importante no tocante a sua sexualidade, demonstrando, assim, sua pouca freqüência às unidades básicas ${ }^{9}$.

A distribuição de preservativos aos adolescentes deve ser uma questão prioritária na formulação das políticas públicas, já que os adolescentes se encontram em situação de vulnerabilidade pelo fato de rejeitarem o preservativo por tabus pessoais e encontrarem empecilhos morais na comunidade. Segundo o Ministério da Saúde do Brasil ${ }^{16}$, os adolescentes e a população em geral poucos usam o preservativo, principalmente os casais em relação estável, mesmo tendo seu duplo benefício, proteção contra DST e prevenção de gravidezes indesejáveis.

Os meios de comunicação são considerados pelos adolescentes como: 0 povo faz errado porque quer, porque a televisão mostra tudo. A televisão explica de vez em quando, mas eu aprendo mais na internet. As músicas de forró são as piores. A gente fica escutando e quer fazer igual. No geral, eles os caracterizam como informativos e influentes no seu jeito de pensar e agir. De fato, os meios de divulgação exercem enorme papel quanto à sexualidade, principalmente entre os adolescentes, pois estimulam o sexo sem barreiras com culto à sensualidade e ao corpo. Negligenciam, entretanto, a educação sexual, tratando a sexualidade de forma sensacionalista com a finalidade de obter grande audiência, sem resultados educativos ${ }^{17}$.

Portanto, percebe-se que, pelo diálogo com os adolescentes, a rede social que os rodeia não se sente responsabilizada pela vulnerabilidade em que os jovens se encontram, negligenciando para outros âmbitos, que também não cumprem o papel de formação na perspectiva saudável, ficando 0 adolescente sob influência do grupo de amigos e da mídia. Entende-se que a família, a escola e a sociedade devem conduzir a criança a partir de uma educação integral, na qual a sexualidade seja incluída, na perspectiva da formação do cidadão crítico, capaz de discernir sua vida no âmbito da promoção da saúde.

\section{Sexualidade e preconceitos enraizados}

Há muitas questões no contexto da sexualidade ainda vivenciadas com dificuldade pelos adolescentes. A primeira questão a ser apresentada pelas falas refere-se às diferentes identidades sexuais (homossexual, heterossexual ou bissexual). Seguindo a communis opinio, os adolescentes também enxergam os padrões de comportamento que a sociedade incorporou como normalidade, inclusive na orientação sexual, como apresentado nas falas: Heterossexual éo que todos nós somos. Heterossexual é apaixonar-se pelo sexo oposto. Éo padrão que devemos seguir.
A religião exerce intensa influência sobre o comportamento e, conseqüentemente, sobre a sexualidade humana. As falas caracterizam esta forte relação na formação destes preceitos: É o normal. Como Deus criou Adão e Eva e o homem e a mulher para se unir. No discurso religioso cristão, apesar de se propagar a idéia de acolhida aos homossexuais, são difundidas representações que caracterizam as práticas homossexuais como "pecado", "anormalidade" e comportamento que se opõe ao "plano divino"18. A idéia de pecado teve forte poder na formação das normas de conduta para o comportamento humano e, apesar de ter sido objeto de algumas modificações com o passar dos tempos, ainda é assunto que causa grande controvérsia.

A homossexualidade e a bissexualidade ainda são vistas como anormalidade pela maioria dos adolescentes, independentemente do gênero: Eu odeio. Sinto nojo. Tenho preconceito. É estranho e anormal. As falas reafirmam pesquisas que apresentam a população homossexual como a mais odiada, refletindo os altos índices de assassinato de natureza homofóbica9. Os participantes do grupo focal masculino apresentaram-se muito rudes neste aspecto: Eu não aceito fácil não. Que fiquem bem longe de mim. É o sério problema da homofobia presente na sociedade contemporânea, que reflete o paradigma da masculinidade estereotipada com a aversão aos homens que não respondem as premissas desde modelo ${ }^{19}$. Apesar disso, podemos perceber um discreto aumento de tolerância aos homossexuais na sociedade: $E u$ respeito. É escolha da pessoa. Gay, bissexual e lésbica. Eu não tenho preconceito não. É normal.

Outras questões a serem discutidas são os entraves que os adolescentes manifestam acerca dos diversos comportamentos sexuais que, entre outros, são o sexo oral, o sexo anal e a masturbação. Os comportamentos sexuais do sexo oral e do sexo anal significam para alguns indivíduos o sentimento de desejo e a possibilidade de prazer, como para outros a transgressão, o nojo, o pecado, uma experiência cercada de mitos, medos e mistérios. 0 sexo anal, em particular para 0 grupo das garotas, dirigiu-se no sentido do prazer, porém sempre com o receio à prática: É o sexo pelo ânus. Tem gente que pensa que é coisa de gay, mas tem mulher que gosta. No grupo dos garotos, a condição não foi tão pacífica, pois, apesar de concordarem com a idéia de que seria uma forma de obtenção de prazer, as referências seriam de preconceito à homossexualidade: Eu não entendendo nada disso não. Pra mim, é sexo pra veado. Enfim, destacou-se a questão dos estereótipos sociais, revelando seus valores tradicionais. Embora alguns expressem um discurso privilegiando a igualdade e a liberdade de escolha de suas identidades e comportamentos sexuais, a idéia central ainda privilegia a hegemonia masculina na descoberta do corpo, do prazer e da liberdade sexual ante a sexualidade da mulher e mantém a homofobia em todos os âmbitos ${ }^{20}$.

Em se tratando da masturbação, sabemos que é uma prática mais comum em adolescentes masculinos do que femininos, mas que se vem equiparando nos últimos anos ${ }^{21}$. Na realidade, porém, esta situação não é vista tão facilmente. Seguindo as representações dos gêneros, os grupos focais refletiram o quanto 
a masculinidade e a feminilidade padecem de um paradigma que proíbe que a masturbação seja praticada da mesma forma entre os gêneros. Apesar de algumas adolescentes perceberem a masturbação como forma de obter prazer e de autoconhecimento, a maioria relatou: É anormal, nojento. Falta de homem ou mulher. Os garotos tanto consideraram que masturbação é sinônimo de abstinência, como seria inadmissível que as suas companheiras praticassem a masturbação nelas mesmas: Os caras que não têm relação fazem com a mão. É falta de mulher. Minha mulher não precisa disso. Não é natural. Pra mulher, é anormal e feio. É falta de macho. Isto se trata de um empecilho, já que a masturbação na adolescência não serve apenas para satisfazer o desejo, ou aliviar a tensão sexual, mas também fornece um meio seguro de experimentação sexual, aumenta a autoconfiança sexual, controla os impulsos sexuais, combate a solidão e descarrega as tensões e 0 estresse geral ${ }^{21}$.

A sexualidade ainda se encontra deturpada e reprimida. 0 atual formato das relações de gênero reflete na sociedade 0 modelo dominado pela masculinidade hegemônica, que reprime as mulheres em geral e os homens que não respondem as premissas da masculinidade estereotipada. A homofobia revela-se como uma das formas de violação de direitos, colocando-se como obstáculo ao acesso e exercício dos direitos sociais por homossexuais e bissexuais, homens e mulheres, negando a livre expressão da sexualidade como um direito humano ${ }^{22}$. Todo esse formato de sociedade machista contribui para a permanência destes paradigmas que englobam a sexualidade e, conseqüentemente, engessam a condição sexual do indivíduo e sua identidade. É preciso estimular o diálogo com os jovens, de modo que eles possam ter a oportunidade de refletir sobre a sexualidade, privilegiando o respeito à identidade sexual e de gênero, o direito ao livre exercício de sua sexualidade, com a devida visibilidade de sua orientação sexual ${ }^{14}$.

\section{Relações de gênero como questão emergencial para reflexão}

As relações desiguais de gênero são empregadas nos mais diversos âmbitos, individuais e coletivos, mantendo barreiras sociais. Estas relações de gênero e suas representações sociais são percebidas pela sociedade de forma "naturalizada", a partir do sistemático estabelecimento das funções e atividades das mulheres e dos homens. Esta naturalização leva a sociedade a enxergar os papéis sociais dos gêneros como imutáveis, conseqüentemente, sustentando a idéia de manutenção das desigualdades. Os adolescentes refletem nas falas esta idéia que remonta erroneamente ao sentido de que os papéis de gênero são atribuições naturais e não culturais: Homem é pra sair e mulher é pra ficar em casa. Os adolescentes, por influências tradicionais, tratam as mulheres como um ser dócil, cordial, cuidador da família e também responsável pelo setor privado do lar; e os homens como capazes, ativos, fortes para o trabalho árduo e devendo responder pelo setor público do trabalho. Por esse sistema de gênero opressor, muitas mulheres não conseguem desenvolver a autoconfiança para levar a vida autonomamente, caracterizando a feminilidade como silêncio e conformação ${ }^{23}$.
Quando os adolescentes do gênero masculino foram questionados sobre como seriam se fossem do gênero feminino, eles afirmaram: Se eu fosse mulher eu seria lésbica porque mulher é bom demais. Se eu fosse mulher eu seria galinha. Meu filme seria queimado porque eu não iria me dar valor, ou seja, percebemos que eles sentem necessidade de se apresentar na condição de sexualmente viris e que esta situação no quadro feminino seria considerada como moralmente inadequada ${ }^{23}$. Quando as adolescentes foram questionadas quanto ao seu comportamento caso elas fossem do gênero masculino, mantiveram o estereótipo masculino: Se eu fosse homem procuraria não ser nem bruto e nem tão romântico. Homem frouxo a mulher pisa em cima. Não gosto de homem fresco. Além disso, expuseram de forma contundente que perpetuariam esta questão de dominação masculina ou ainda explorariam mais: Se eu fosse homem eu ficaria com todas as meninas, seria bruto, não teria sentimento e nem carinho. Se eu fosse homem comeria todas sem peso na consciência. Estes depoimentos assustam, por se perceber que as mulheres, além de não se perceberem exploradas e reprimidas, apontam para a continuação e até deterioração de suas condições atuais. Elas encaram o contexto de gênero atual como fato natural da existência do ser humano, sendo necessária para o bem-estar de todos. Os argumentos, tanto dos garotos como das garotas, seguem de forma a sufocar a sensibilidade masculina, por considerar um sentimento feminino, caso contrário, não serão considerados machos ${ }^{24}$.

Quanto à virgindade, os garotos ainda fazem alusão a essa condição como critério de valor para a mulher e a consideram determinante para o reconhecimento socialmente aceito a elas: Se eu fosse mulher eu teria que me dar valor e respeito. Homem só namora com mulher direita. A minha mulher tem que ser virgem pra casar". A forma social de perceber a iniciação sexual é guiada pela formulação da masculinidade, amparada em rituais de socialização, como a pressão exercida pelos amigos. Com relação à iniciação sexual das moças, a ausência de experiência sexual é percebida como estratégia de seleção para relacionamentos que entrelacem o sexual com o afetivo, em um plano de relação estável, do tipo matrimonial ${ }^{9}$.

Quando o assunto foi prevenção das DSTs e gravidezes indesejáveis, eles referiram: Aqui o povo sabe; não faz porque não quer. Expuseram condições que os levam a se tornar vulneráveis às DSTs: Tem confiança na namorada. Sem preservativo é melhor. Não tem preservativo na hora. Não pensa nas conseqüências, só no prazer. As garotas refletiram o grau de subordinação ao desejo masculino e apresentam-se submissas à vontade do namorado, cedendo seus corpos sem proteção: Não vou perder meu namorado por causa da camisinha. Os casais geralmente não negociam o uso do preservativo, já que isto estaria pondo em dúvida a fidelidade de ambos e, além disso, a mulher ainda está na posição reprimida e jamais deverá portar o preservativo consigo, mantendo-se calada para não provocar desconfiança do companheiro ${ }^{25}$. A virgindade da garota, imaginada pelo sangramento na relação, é vista como um aval para praticar o sexo sem camisinha e não ter risco às DSTs: Se a menina sangrar, ela é virgem e não tem perigo de pegar DST. A primeira relação sexual é uma das razões para 0 
comportamento sexual desprotegido entre adolescentes, já que eles não acreditam na existência do risco de gravidez e doenças ${ }^{26}$.

Com todos estes depoimentos que levam a vulnerabilidade juvenil às DSTs, há adolescentes que se percebem conscientes do problema, estando fora da situação de risco, já que o uso do preservativo é prioridade: Quem vê cara não vê coração.

A condição atual das relações de gênero em muito influencia a vulnerabilidade a que os adolescentes estão expostos. Os adolescentes do grupo focal masculino sentiram a necessidade de apresentarem-se como sexualmente potentes por penetrarem o corpo feminino, serem livres para expressarem seus desejos sexuais, infiéis, detentores do comando na relação conjugal, naturalizando a sua condição de mandar e de a mulher obedecer, refletindo a masculinidade hegemônica e estereotipada. As adolescentes do grupo focal feminino, mesmo referindo injustiças na relação com o namorado, apresentaram falas que reproduziam a condição atual de submissão feminina aos desejos masculinos, principalmente no âmbito da sexualidade.

\section{CONSIDERAÇÕES FINAIS}

A adolescência, como etapa entre o ser criança e ser adulto, é o período fundamental de formação da identidade sexual e da cultura em torno da sexualidade do ser, por isso a importância de perceber quais as percepções que eles têm acerca da sexualidade. Os adolescentes que participaram do estudo sentiram-se livres durante os diálogos dos grupos focais e puderam expor detalhes de suas intimidades conjugais e seus contextos sociais. Nas conversas, foi possível perceber as crenças,

\section{Referências}

1. Pedro JM. Traduzindo o debate: 0 uso da categoria gênero na pesquisa histórica. História 2005; 24 (1): 77- 98.

2. Pedro JM. A experiência com contraceptivos no Brasil: uma questão de geração. Rev Bras Hist 2003; 23(45): 239-60.

3. Carreno I, Costa JSD. Uso de preservativos nas relações sexuais: estudo de base populacional. Rev Saúde Pública 2006; 40(4): 720-26.

4. Jiménez AL, Gotlieb SLD, Hardy E, Zaneveld LJD. Prevenção de doenças sexualmente transmissíveis em mulheres: associação com variáveis sócio-econômicas e demográficas. Cad Saúde Pública 2001 fev; 17 (1): 55-62.

5. Heidemann M. Adolescência e saúde: uma visão preventiva: para profissionais de saúde e educação. Petrópolis (RJ): Vozes; 2006.

6. Villela WV, Doreto DT. Sobre a experiência sexual dos jovens. Cad Saúde Pública 2006 nov; 22(11): 2467-72.

7. Westphal MF, Bogus CM, Faria MM. Grupos focais: experiências precursoras em programas educativos em saúde no Brasil. Bol Oficina Sanit Panam 1996; 120(6): 472-81.

8. Soares CB, Reale D, Brites CM. Uso de grupo focal como instrumento de avaliação de programa educacional em saúde. Rev. Esc. Enferm USP 2000 set; 34(3): 317-22. mitos, preconceitos e tabus que persistem em existir no âmbito da sexualidade e a rede social que os influencia para essa condição. De todos esses, as relações de gêneros desiguais e injustas são as que mais prejudicam o pleno desenvolvimento da sexualidade e originam características e vulnerabilidades particulares.

A vulnerabilidade dos indivíduos às DSTs sempre deve ser lembrada como condição influenciada pela atual relação de gênero desigual e como os indivíduos se moldam a esta situação: o homem se expondo às DSTs por sentir necessidade de se manifestar como sexualmente potente e poligâmico, não querendo usar preservativo, e as mulheres na circunstância de submissão ao desejo sexual masculino, incumbindo seus desejos e anseios pessoais.

As relações de gênero são expressas nos diversos âmbitos individuais, coletivos e sociais, e, para torná-las eqüitativas, deve ser promovida a remoção de barreiras em todas as relações sociais. A escola tem papel fundamental na formação destes cidadãos no âmbito da igualdade dos gêneros; e isto deve estar dentro da formulação de políticas públicas que tencionam esta transformação.

A sociedade em geral, independentemente de gênero e idade, incorpora os estereótipos sexuais e conserva seus paradigmas. Portanto, para alcançar a igualdade de gênero, as pessoas precisam destituir-se desta condição moldada desde a infância; as mulheres podem exercer sua sexualidade de forma plena e igualitária, negociando com os companheiros a relação saudável que gostariam de seguir, sem a atual repressão social, e os homens poderiam seguir outro modelo de masculinidade e sentirem-se plenos nas suas condutas, sem a opressão do atual modelo hegemônico.

9. Castro MG, Abramovay M, Silva LB. Juventude e sexualidade. Brasília (DF): UNESCO/MEC/Coordenação Nacional de SDT/AIDS/Secretaria Especial de Políticas para as Mulheres/ Instituto Airton Senna; 2004. 10. Bardin L. Análise de conteúdo. Lisboa (PT): Ed 70; 1977.

11. Ministério da Saúde (BR). Conselho Nacional de Saúde-CNS. Resolução $n^{0} 196$ de 10 de outubro de 1996. Dispõe sobre as diretrizes e normas regulamentadoras de pesquisas envolvendo seres humanos. Bioética 1996; 4(2 supl):15-25.

12. Harrison, M. 0 primeiro livro do adolescente sobre amor, sexo e AIDS. Porto Alegre(RS): Artes Médicas; 1995.

13. Taquette, SR, Vilhena MM, Paula MC. Doenças sexualmente transmissíveis e gênero: um estudo transversal com adolescentes no Rio de Janeiro. Cad. Saúde Pública 2004 fev; 20 (1): 282-90.

14. Ministério da Saúde (BR). PNDST e AIDS. Diretrizes para implantação do Projeto Saúde e Prevenção nas escolas. Brasília (DF); 2006.

15. Taquette SR, Andrade RB de, Vilhena MM, Paula MC. A relação entre as características sociais e comportamentais da adolescente e as doenças sexualmente transmissíveis. Rev Assoc Med Bras; 2005; 51 (3): 148-52.

16. Ministério da Saúde (BR). Manual de controle de doenças sexualmente transmissíveis. Brasília (DF): Coordenação Nacional de DST e AIDS/ Secretaria de Políticas de Saúde; 1999.

17. Bruno ZB. Meios de comunicação versus DST e AIDS. In: Passos MR. Deessetologia: doenças sexualmente transmissíveis, DST 5. Rio de Janeiro(RJ): Cultura Médica; 2005. 
18. Giumbelli E, organizador. Religião e sexualidade: convicções e responsabilidades. Rio de Janeiro(RJ): Garamond; 2005.

19. Korin D. Novas perspectivas de gênero em saúde. Adolesc Latinoam. 2001 mar; 2(2): 67-79.

20. Carvalho AM, Rodrigues CS, Medrado KS. Oficinas em sexualidade humana com adolescentes. Est Psicol 2005; 10: 377-84.

21. Lopez F, Fuertes A. Para entender a sexualidade. Tradução de MS Gonçalvez , AU Sobral. São Paulo(SP): Loyola; 1992.

22. Ministério da Saúde(BR). Secretaria de Atenção à Saúde. Departamento de Aç̃̃es Programáticas Estratégicas. Marco teórico e referencial: saúde sexual e saúde reprodutiva de adolescentes e jovens. Brasília (DF); 2006.

23. Cabral FB, Ressel LB, Landerdahl MC. Consulta de enfermagem: estratégia de abordagem à gestante na perspectiva de gênero. Esc Anna Nery Rev Enferm 2005 dez; 9(3): 459-65.

24. Saffioti HIB. 0 poder do macho. São Paulo (SP): Moderna; 1987. 25. Schall V. A prevenção de DST/AIDS e do uso indevido de drogas a partir da pré-adolescência: uma abordagem lúdico-afetiva. In: Ascselrad G, organizador. Avessos do prazer: drogas, aids e direitos humanos. Rio de Janeiro (RJ): FIOCRUZ; 2000.
26. Romero KT, Medeiros EHGR, Vitalle MSS, Wehba J. Romero KT, Medeiros EHGR, Vitalle MSS, Wehba J. 0 conhecimento das adolescentes sobre questões relacionadas ao sexo. Rev. Assoc. Med. Bras; 2007 jan./fev; 53(1): 14-19.

\section{Sobre as Autoras}

\section{Cibele Almeida Torres}

Universidade Federal do Ceará, Fortaleza.

\section{Eveline Pinheiro Beserra}

Universidade Federal do Ceará, Fortaleza.

\section{Maria Grasiela Teixeira Barroso}

Universidade Federal do Ceará, Fortaleza. 